\title{
Experimental Study of Fiber Length and Orientation in Injection Molded Natural Fiber/Starch Acetate Composites
}

\author{
Heidi Peltola, ${ }^{1}$ Bo Madsen, ${ }^{2}$ Roberts Joffe,${ }^{3}$ and Kalle Nättinen ${ }^{1}$ \\ ${ }^{1}$ VTT Technical Research Centre of Finland, P.O. Box 1300, 33101 Tampere, Finland \\ ${ }^{2}$ Materials Research Division, Risø National Laboratory for Sustainable Energy, Technical University of Denmark, \\ P.O. Box 49, 4000 Roskilde, Denmark \\ ${ }^{3}$ Department of Applied Physics and Mechanical Engineering, Luleå University of Technology, 97187 Luleå, Sweden \\ Correspondence should be addressed to Kalle Nättinen, kalle.nattinen@vtt.fi
}

Received 29 March 2011; Revised 21 June 2011; Accepted 23 June 2011

Academic Editor: Krishnan Jayaraman

Copyright ( $\odot 2011$ Heidi Peltola et al. This is an open access article distributed under the Creative Commons Attribution License, which permits unrestricted use, distribution, and reproduction in any medium, provided the original work is properly cited.

Composite compounds based on triethyl citrate plasticized starch acetate and hemp and flax fibers were prepared by melt processing. Plasticizer contents from 20 to $35 \mathrm{wt} \%$ and fiber contents of 10 and $40 \mathrm{wt} \%$ were used. The compounded composites were injection molded to tensile test specimens. The effect of processing, melt viscosity and fiber type on the fiber length was investigated. The lengths of fully processed fibers were determined by dissolving the matrix and measuring the length of the remaining fibers by microscope analysis. A clear reductive effect of the processing on the fiber length was noticed. A reduction of fiber length along the increasing fiber content and the decreasing plasticizer content was also detected. This reduction originated from the increasing shear forces during compounding, which again depended on the increased viscosity of the material. Hemp fibers were shown to remain longer and fibrillate more than flax fibers, leading to higher aspect ratio. Thus, the reinforcement efficiency of hemp fibers by the processing was improved, in contrast with flax fibers. In addition, the analysis of fiber dispersion and orientation showed a good dispersion of fibers in the matrix, and a predominant orientation of the fibers in the melt flow direction.

\section{Introduction}

An increasing interest towards the use of biobased polymers instead of conventional petroleum-based plastic materials can be detected worldwide. Progressing technologies, rising prices of finite resources, and new environmental legislation together with more environmentally concerned consumers are creating a need to compensate petroleum-based materials with bio-based plastics. Within various biomaterials, especially starch-based bioplastics have been widely studied and used due to their low price and good availability. However, the properties of bio-based plastics do not always meet the material requirements of certain applications. Fiber reinforcement of the plastic material can provide higher mechanical properties and thereby wider application possibilities. The most common fiber materials for reinforcement of plastics are glass, carbon, aramid, and polyethylene. To produce natural fiber reinforced composites, various cellulosic fibers from flax, hemp and wood can be used. In thermoplastic starch composites, flax and ramie fibers have been used, resulting in four times higher tensile strengths than the neat plastics [1]. Starch acetates have earlier been reinforced with cellulosic fibers to give composites with enhanced mechanical properties, shock absorbance, and processability $[2,3]$. In the processing of the natural fiber composites, the variable and somewhat sensitive nature of the natural fibers needs to be taken into account. The fibers are inevitably reduced in length during the pelletising, compounding, and molding processes. In addition, the dispersion, and orientation of the fibers in the composites are also influenced by processing conditions. These changes are actuated by shear forces during processing, which in turn depend on the melt viscosity. Plasticized starch acetates are suitable to be used as model matrix materials in order to analyze these changes, since the melt viscosity and the mechanical properties of the starch acetate can be adjusted by the plasticizer content [3]. An improved 
knowledge of the influence of biocomposite processing and composition on the fiber length, dispersion and orientation is needed in order to minimize iterative product design.

\section{Experimental}

2.1. Materials. For acetylation of the starch, a high amylose (62\%) corn starch (Cerestar AmyloGel 03003) was purchased from Cargill-Cerestar BVBA (Mechelen, Belgium). The starch acetates were prepared according to a procedure by Lammers et al. [4] to a high degree of substitution (DS 2.6) at VTT Rajamäki. For plasticizing, triethyl citrate (TEC) by the product name of Citroflex 2 was purchased from Morflex Inc. (North Carolina, USA) and obtained from OneMed (Finland). Flax and hemp fibers were delivered by Ekotex (Poland) and BaFa GmbH (Germany), respectively, both cut into approximately $12 \mathrm{~mm}$ length to ease the handling, and they were afterwards then pelletised for compounding trials. No surface treatments or compatibilization was used, since the cellulose-based fibers previously have been shown to be well compatible with the starch matrix [3].

2.2. Processing. Starch acetate was initially prepared in preplasticized form, containing $15 \mathrm{wt} \%$ of TEC. The material was further plasticized to TEC contents of 20, 25, 32.5, and $35 \mathrm{wt} \%$ using a twin-screw extruder (ZE $25 \times 48 \mathrm{D}$, Berstorff $\mathrm{GmbH}$, Hannover, Germany) with corotating mixing screws. Composite compounds with fiber contents of 10 and $40 \mathrm{wt} \%$ were then prepared from pelletised flax and hemp fibers, using the same twin-screw extruder as described above. These samples were then injection molded with Engel injection molding machine (ES 200/50 HL, Engel Austria GmbH, Schwertberg, Austria) to ISO 3167 tensile test specimen. Applied parameters depended on the composition of the molded material, temperatures being approximately from 130 to $200^{\circ} \mathrm{C}$, pressures from 30 to 80 bars, and postpressures from 10 to 70 bars.

2.3. Fiber Length Analysis. For each composite compound, pieces of $(\mathrm{mm}) 4 \times 20 \times 20$ were cut from the tensile test specimens and dissolved in hot chloroform. The remaining fiber fraction was collected and the fiber length distribution was determined by optical microscopy and image analyses.

2.4. Fiber Dispersion and Orientation. Optical microscopy was used to study the dispersion and orientation of fibers by making and analyzing images of polished composite crosssections cut with different angles to the flow direction of the injection molded samples. The dispersion and orientation of the fibers were determined by image analysis using ImagePro software.

2.5. Mechanical Properties. The tensile test specimens were kept in a room with standard conditions $\left(23^{\circ} \mathrm{C}, 50 \%\right.$ relative humidity) for at least five days before testing. The ISO-527 and ISO-179 standards were used in the mechanical testing of the specimens. Tensile tests were performed using an Instron 4505 Universal Tensile Tester (Instron Corp., Canton, MA, USA) and an Instron 2665 Series High Resolution Digital

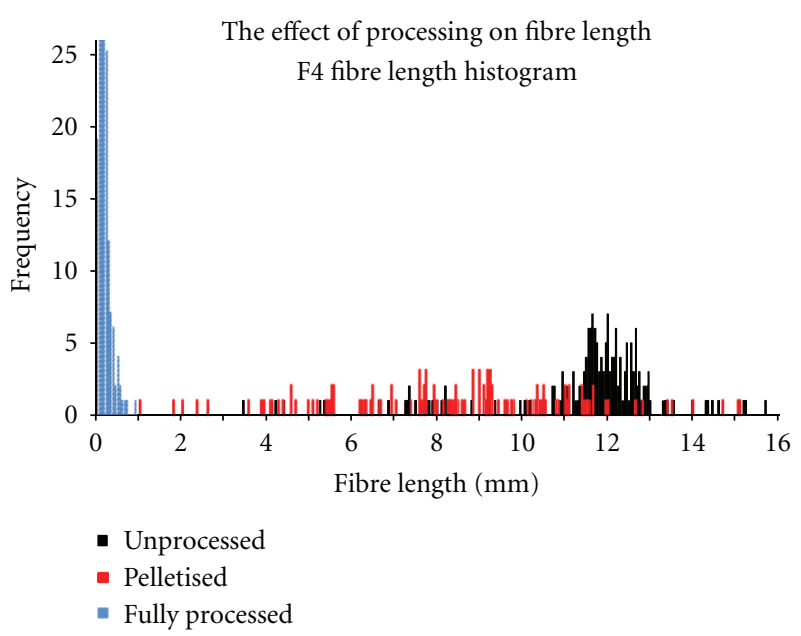

Figure 1: Histograms of fiber lengths of unprocessed, pelletised, and fully processed flax fibers up to $16 \mathrm{~mm}$. Frequencies of the fully processed fibers outside $y$-scale are $81(0.05<x \leq 0.10 \mathrm{~mm}), 83$ $(0.10<x \leq 0.15 \mathrm{~mm})$, and $42(0.15<x \leq 0.20 \mathrm{~mm})$.

Automatic Extensometer (Instron Corp., Canton, MA, USA) with $10 \mathrm{kN}$ load cell and a $5 \mathrm{~mm} / \mathrm{min}$ cross-head speed. Impact strengths were determined by using Charpy Ceast Resil 5.5 Impact Strength Machine (CEAST S.p.a., Torino, Italy). Impact strength tests were performed on unnotched specimens.

\section{Results}

3.1. Fiber Length. The change of the fiber length in the process of reinforcing starch acetate with natural fibers was studied from three different aspects: (1) process steps, (2) melt viscosity, and (3) fiber type.

3.1.1. Process Steps. Figure 1 shows the histograms of lengths of unprocessed, pelletised, and fully processed flax fibers. The full processing includes pelletising, compounding and injection molding of the composite with $20 \mathrm{wt} \%$ of TEC and $40 \mathrm{wt} \%$ of flax fibers. From the figure, the effect of processing on the reduction of fiber length can clearly be detected. The average length of the unprocessed flax fibers is $11.7 \mathrm{~mm}$ with standard deviation of $2.7 \mathrm{~mm}$. Fiber pelletising has a slight effect on the fiber length: after pelletising, the average fiber length decreases to $10.4 \mathrm{~mm}$ with standard deviation of $6.1 \mathrm{~mm}$. After full processing, the fiber length reduces extensively. The average fiber length of the fully processed fibers is $0.151 \mathrm{~mm}$ with standard deviation of $0.105 \mathrm{~mm}$. The length reduction of the fully processed fibers is controlled by the conditions during compounding and injection molding of the composite: processing temperature, screw configuration, and the resulting shear forces. The range of fibre content in the samples necessitated some parameter variation in injection molding to give specimen of good quality.

3.1.2. Melt Viscosity. Both the plasticizer and fiber content of the composite have an effect on the viscosity of the composite melt, which in turn influences the fiber length reduction 
TABle 1: Mean fiber lengths, standard deviations, minimum and maximum lengths of the fully processed flax, and hemp fibers in the composites.

\begin{tabular}{|c|c|c|c|c|c|c|}
\hline Fiber & $\begin{array}{c}\text { Fiber content } \\
(\mathrm{wt} \%)\end{array}$ & $\begin{array}{c}\text { TEC content } \\
(\mathrm{wt} \%)\end{array}$ & $\begin{array}{c}\text { Mean Fiber } \\
\text { Length }(\mathrm{mm})\end{array}$ & $\begin{array}{c}\text { Standard } \\
\text { Deviation }(\mathrm{mm}) \\
\end{array}$ & $\begin{array}{l}\text { Min. Length } \\
(\mathrm{mm})\end{array}$ & $\begin{array}{c}\text { Max. Length } \\
(\mathrm{mm})\end{array}$ \\
\hline Flax & 10 & 20 & 0.347 & 0.257 & 0.043 & 1.506 \\
\hline Flax & 10 & 25 & 0.317 & 0.268 & 0.024 & 1.566 \\
\hline Flax & 10 & 32.5 & 0.334 & 0.262 & 0.028 & 1.282 \\
\hline Flax & 10 & 35 & 0.498 & 0.473 & 0.016 & 2.686 \\
\hline Flax & 40 & 20 & 0.151 & 0.105 & 0.028 & 0.697 \\
\hline Flax & 40 & 25 & 0.252 & 0.196 & 0.024 & 1.100 \\
\hline Flax & 40 & 32.5 & 0.293 & 0.256 & 0.020 & 1.572 \\
\hline Flax & 40 & 35 & 0.297 & 0.247 & 0.033 & 1.218 \\
\hline Hemp & 40 & 32.5 & 0.544 & 0.560 & 0.029 & 2.459 \\
\hline
\end{tabular}

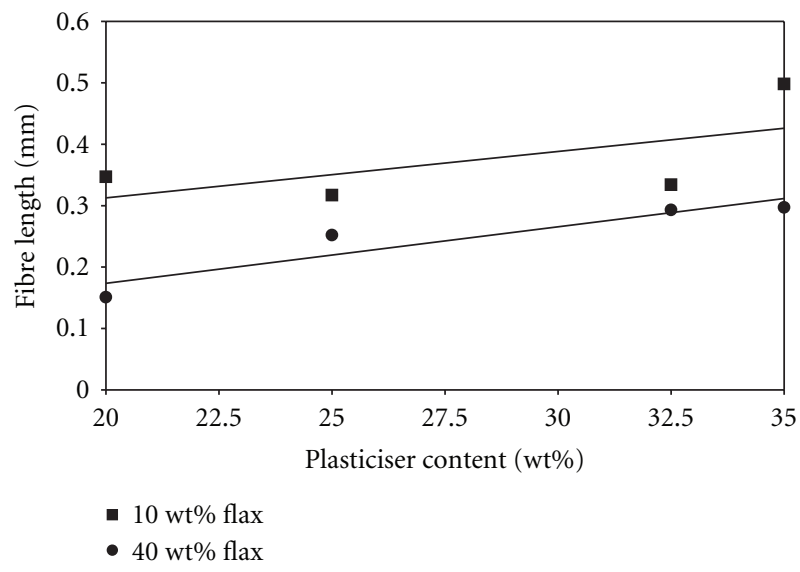

Figure 2: Mean lengths of flax fibers after full processing. The fibers were extracted from composites with 10 and $40 \mathrm{wt} \%$ fiber content and with variable plasticizer content.

during processing. Composites compounded with 10 and $40 \mathrm{wt} \%$ of fibers and plasticizer contents of $20,25,32.5$ and $35 \mathrm{wt} \%$ were selected to study the effect of plasticizer and fiber content on the fiber lengths of the fully processed flax fibers. Table 1 shows the compositions of the selected composites in addition to mean fiber lengths, standard deviations and minimum and maximum lengths of the fully processed fibers.

Figure 2 shows the mean fiber lengths of flax fibers in the composites with 10 and $40 \mathrm{wt} \%$ fiber content, as a function of plasticizer content. Mean values are used for the sake of simplicity, although the distribution of fiber lengths is not following a Gaussian distribution. Also, the large scatter of the fiber lengths is not shown in the figure, since the purpose is only to indicate a tendency of the change in fiber length. As seen in the figure, based on the mean values, it is indicated that an increase in the fiber content of the composite results in reduced fiber lengths. The fiber length reduction is also increased when plasticizer content is decreased. However, the effect of the plasticizer content is

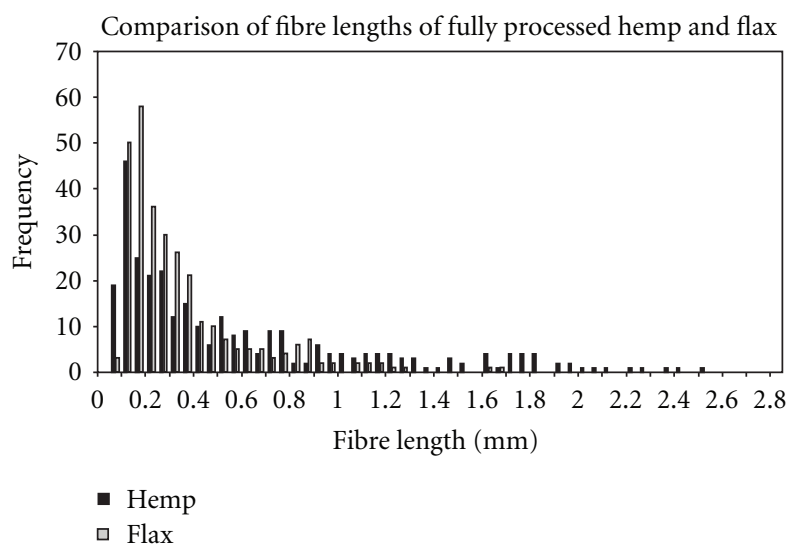

Figure 3: Comparison of fiber length distributions of fully processed hemp and flax fibers.

not markedly affected by the fiber content, which can be seen from the almost identical slopes of the two trend lines. The scatter of data seen in Figure 2 may be partially caused by the differences in the injection molding parameters between different samples. Although a degree of variation is possible, the well-predictable mechanical properties discussed in our earlier work [3] suggest that the resultant effect on the fibre lengths is not very substantial.

Both with plasticizer and fiber content, the fiber shortening originates from the increasing shear forces during compounding, which again depends on the viscosity of the material. Addition of fibers into the matrix polymer increases the viscosity of the melt and therefore also the fiber cutting increases. The same phenomenon relates to adjustment of plasticizer levels. With less plasticizer, the melt is more viscous and therefore more susceptible to shear forces during compounding. Along the addition of plasticizer, less energy is absorbed by the composite melt from the mixing work done by the kneaders and mixers in the compounder and as a result, the fibers are split and cut to a smaller extent. 
TABLE 2: Mechanical properties of flax and hemp fiber composites.

\begin{tabular}{lccccc}
\hline Fiber & Fiber content $(\mathrm{wt} \%)$ & TEC content $(\mathrm{wt} \%)$ & Tensile Strength $(\mathrm{MPa})$ & Elastic Modulus $(\mathrm{GPa})$ & Impact Strength $\left(\mathrm{kJ} / \mathrm{m}^{2}\right)$ \\
\hline Flax & 10 & 20 & 35.0 & 3.14 & 2.4 \\
Flax & 10 & 25 & 24.9 & 2.37 & 2.2 \\
Flax & 10 & 32.5 & 15.7 & 1.57 & 2.9 \\
Flax & 10 & 35 & 12.1 & 1.12 & 4.8 \\
Flax & 40 & 20 & 50.7 & 4.05 & 5.2 \\
Flax & 40 & 25 & 45.8 & 6.01 & 6.1 \\
Flax & 40 & 32.5 & 33.7 & 5.63 & 7.6 \\
Flax & 40 & 35 & 28.8 & 5.14 & 7.4 \\
Hemp & 40 & 32.5 & 26.6 & 4.45 & 8.8 \\
\hline
\end{tabular}

The plasticizer and fiber contents affect also the mechanical properties of the composites. Table 2 shows the tensile strength, elastic modulus, and impact strength values of the composites with varying compositions. Increasing plasticizer content leads to decreased tensile strength and elastic modulus, but improved impact strength properties. On the other hand, the increase in fiber content results in overall higher mechanical properties of the composites. The effect of plasticizer and fiber contents on the mechanical performance of the composites as well as the stress-strain behavior are addressed in details elsewhere $[3,5]$.

3.1.3. Fiber Type. The effect of fiber type on the fiber length change during processing was studied by determining the fiber lengths in the composites containing $40 \mathrm{wt} \%$ hemp and flax fibers and $32.5 \mathrm{wt} \%$ TEC. The histograms of the lengths of fully processed hemp and flax fibers are shown in Figure 3. Full processing seems to result in higher level of length reduction of flax fibers than of hemp fibers (Table 3 ). The length of unprocessed flax fibers are about the same as hemp fibers. The fully processed hemp fibers are kept longer than flax fibers: the mean lengths of fully processed flax and hemp fibers are 0.293 and $0.544 \mathrm{~mm}$, respectively.

Although the length of the fibers is crucial for the reinforcing effect, the more important parameter is the fiber aspect ratio (length to diameter ratio). Therefore, simultaneously to preserving the fiber length, the width (diameter) of the fiber should ideally be decreased in order to increase the fiber aspect ratio which governs the reinforcement efficiency of the fibers in the composites [6]. The most effective fiber reinforcement is achieved if the length of the fiber exceeds the critical fiber length, which is also depend on the diameter of the fiber [7]. In glass fiber-reinforced polyamide 6,6 composites, tensile strength has been found to increase linearly with decreasing fiber diameter [8]. In addition, fibrillation of the fiber bundles into single fibers is essential to increasing both the longitudinal and transverse strengths of the material. In nonseparated fiber bundles low transverse strengths is observed due to the weak interaction between the individual fibers. Therefore, if the composite contains non-separated fiber bundles, the failure of the material will occur prematurely by initiation from cracks within the material (within fiber bundles). On the other hand, if the fiber bundles are fibrillated into single fibers, the weak interfaces inside the bundles disappear and are replaced by the (assumed) stronger interfaces between single fiber and the matrix. Table 3 shows the mean widths of unprocessed and fully processed flax and hemp fibers, and this can be observed in the images of the fibers in Figure 4. Although the fiber length reduction of hemp fibers during processing is not as extensive as with flax fibers, the hemp fibers tend to fibrillate more easily and therefore the fiber width reduces more compared to flax fibers. The calculated aspect ratios are also shown in Table 3. For the hemp fibers, the fiber aspect ratio is increased from 28 to 42 during processing which will lead to better stress transfer from matrix to fiber according to the shear lag model [6]. Therefore, in this case, the reinforcement efficiency of the fibers is actually improved by the processing. For the flax fibers, the fiber aspect ratio is decreased from 29 to 15 , subsequently reducing the reinforcement efficiency of the fibers. The influences of the fiber aspect ratios (in addition to effects of plasticizer content, fiber content, and fiber orientation) on the mechanical properties of the composites are analyzed elsewhere [5].

3.2. Fiber Dispersion and Orientation. The degree of fiber dispersion and orientation was investigated by optical microscopy of polished cross-sections of composites with $20 \mathrm{wt} \%$ flax fibers and $20 \mathrm{wt} \%$ plasticizer. Two representative images of cross-sections along and perpendicular to the melt flow direction are shown in Figure 5. Both images show that the fibers are well dispersed in the matrix with no large fiber agglomerates which would tend to restrict matrix impregnation and increase the porosity content. The observed good fiber dispersion is supported by measurements of low porosity in the composites $[3,5]$. The two images in the figure show very clearly that the fibers are predominantly oriented in the melt flow direction of the composite samples since the cross-sections of the fibers are in general more elongated in Figure 5(a) than in Figure 5(b).

Images of composite cross-sections with different angles $\left(0,30,60\right.$, and $\left.90^{\circ}\right)$ to the flow directions were analyzed. An angle of $0^{\circ}$ corresponds to a cross-section perpendicular to the flow direction (such as the one shown in Figure 5(b)). See the inserted drawing in Figure 6 for an illustration of 
TABle 3: Mean lengths, widths, standard deviations, and aspect ratios of unprocessed and fully processed hemp and flax fibers extracted from composites with fiber content of $40 \mathrm{wt} \%$ and plasticizer content of $32.5 \mathrm{wt} \%$.

\begin{tabular}{lcccccc}
\hline & & Unprocessed & & & Fully processed \\
Fiber & Fiber Length $(\mathrm{mm})$ & Fiber Width $(\mathrm{mm})$ & Aspect Ratio & Fiber Length $(\mathrm{mm})$ & Fiber Width (mm) & Aspect Ratio \\
\hline Hemp & $12.62 \pm 4.30$ & $0.458 \pm 0.143$ & 28 & $0.544 \pm 0.560$ & $0.013 \pm 0.008$ \\
Flax & $11.74 \pm 2.70$ & $0.403 \pm 0.128$ & 29 & $0.293 \pm 0.256$ & $0.019 \pm 0.007$ \\
\hline
\end{tabular}

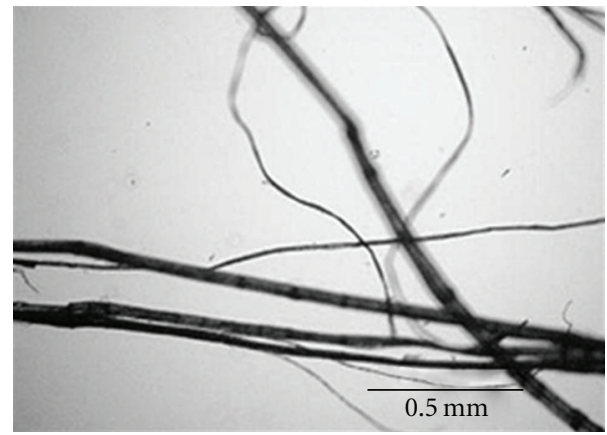

(a)

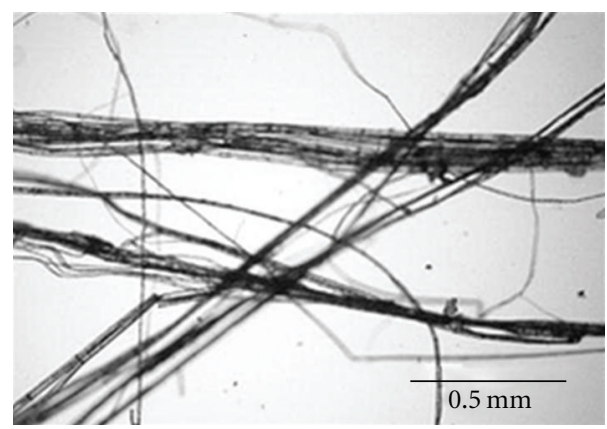

(c)

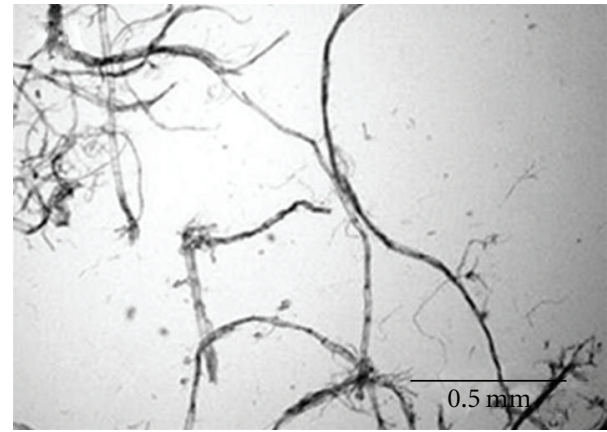

(b)

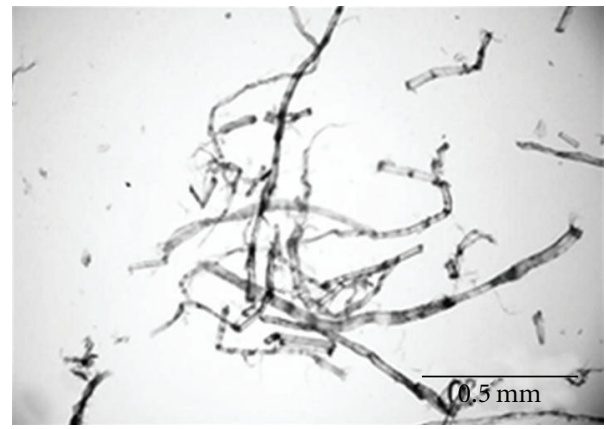

(d)

Figure 4: Optical microscopy images of hemp and flax fibers: (a) unprocessed (b) and fully processed hemp fibers; (c) unprocessed and (d) fully processed flax fibers.

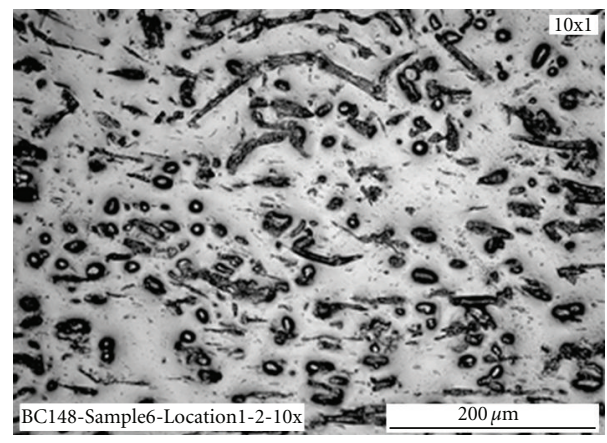

(a)

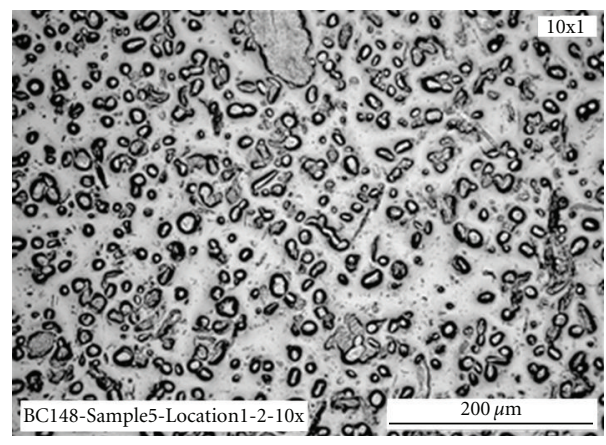

(b)

FIGURE 5: Optical microscopy images of cross-section of composite sample (a) along and (b) perpendicular to the flow direction.

the correlation between the cross-sectional angles and the flow direction of the fibers. In the images of composite cross-sections, elliptical outlines were fit to the fiber crosssections by image analysis, and the aspect ratios (minor diameter/major diameter) of the ellipses were recorded. An aspect ratio of 1.0 designates at circular fiber cross-section, where larger aspect ratios designate more elongate fiber cross-sections, and as such the fiber aspect ratios can be used to quantify the fiber orientation. Figure 6 shows the cumulative frequency distributions of fiber aspect ratios measured from images of composite cross-sections cut at different angles to the flow direction. All cross-sections are 


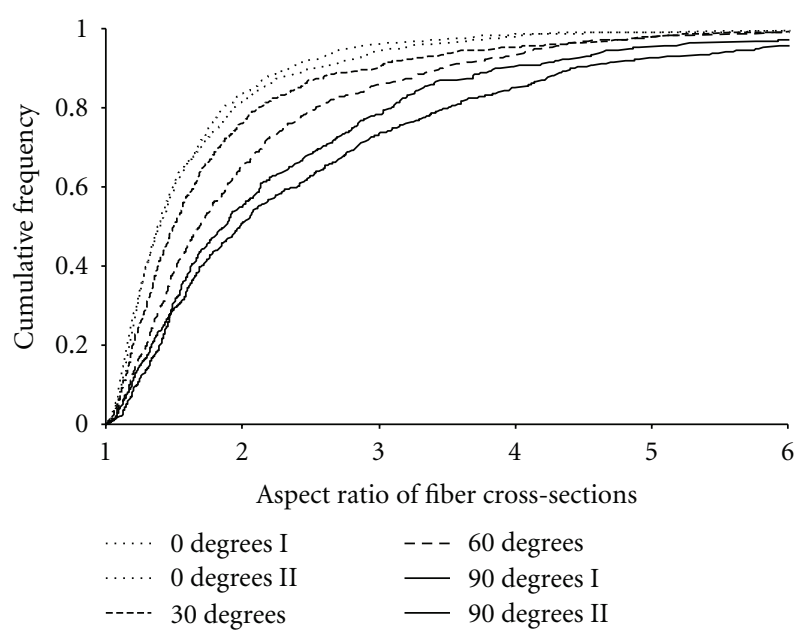

Figure 6: Cumulative frequency distributions of fiber aspect ratios. The inserted drawing shows the correlation between the crosssectional angles and the flow direction of the fibers in the injection molded tensile specimens.

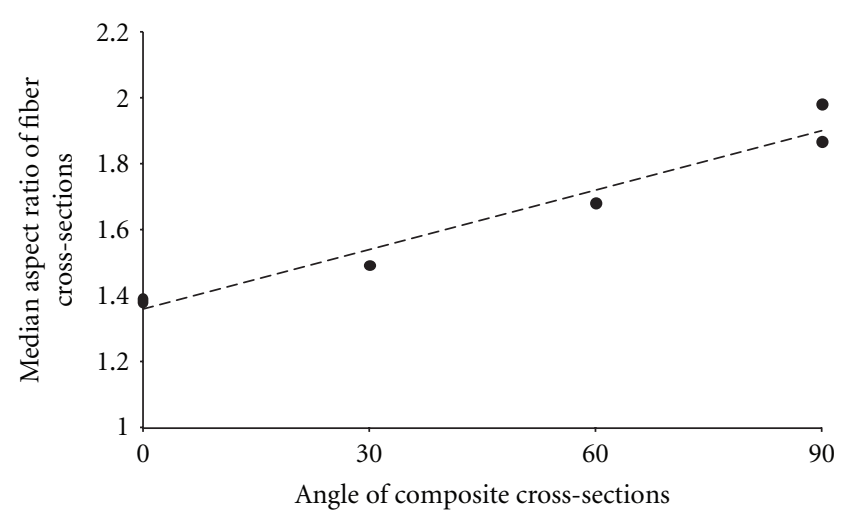

Figure 7: Median aspect ratio of fiber cross-sections as a function of angle of composite cross-section.

from the same type of composite (20 wt $\%$ flax fibers, $20 \mathrm{wt} \%$ plasticizer). As expected, the curves in Figure 6 are shifted downward as a function of angle, which supports the above qualitatively assessed finding of Figure 5 that the fibers are predominantly oriented in the flow direction. In Figure 7, the median aspect ratio (at a cumulative frequency of 0.50 ) of the fibers is plotted as a function of the angle, and this gives a linear relationship with a positive slope. A similar preferred fiber orientation has also been shown previously in a study of injection molded glass fiber/polyamide composites where the fiber orientation factor was estimated to be about 0.80 [8]. In the same study, the fiber content was found to have no influence on the fiber orientation. For the natural fiber/starch acetate composites investigated in the present study, future work will be addressed to obtain data for composites with variable fiber and plasticizer content in order to be able to quantify how this will affect the fiber orientation.

\section{Conclusions}

The effect of processing-pelletising, compounding, and injection molding — on the reduction of fiber dimensions in composites of triethyl citrate plasticized starch acetate with hemp and flax fibers was determined by optical microscopy. A correlation between the fiber length and the plasticizer and fiber content of the composite was found. The shear force level in the compounding and injection processes is proportional to the composite melt viscosity, which again is a result of the fiber and plasticizer content. A reduction of fiber lengths of both hemp and flax along the increasing fiber content and the decreasing plasticizer content was observed. The comparison of the lengths of fully processed hemp and flax fibers revealed that the hemp fibers remained longer than flax fibers. Moreover, higher level of fibrillation occurred with hemp fibers, producing lower fiber widths than those of the flax fibers. Therefore, in case of hemp fibers, the fiber aspect ratio increased from 28 to 42 by the processing, whereas the fiber aspect ratio of flax fibers was reduced from 29 to 15 . This indicates that the reinforcement efficiency of hemp fibers was improved by the processing, on the contrary to the reduced reinforcement efficiency of flax fibers. In a composite containing $20 \mathrm{wt} \%$ flax and $20 \mathrm{wt} \%$ triethyl citrate, good dispersion of fibers was detected by image analysis of the composite crosssections. It was found that the fibers were predominantly orientated in the melt flow direction of the composite samples.

\section{Acknowledgment}

The work was partly financed by the EU sixth framework Program Project New classes of engineering composite materials from renewable resources, BIOCOMP. IP 515769-2.

\section{References}

[1] M. Wollerdorfer and H. Bader, "Influence of natural fibres on the mechanical properties of biodegradable polymers," Industrial Crops and Products, vol. 8, no. 2, pp. 105-112, 1998.

[2] R. Narayan, M. Kotnis, H. Tanaka, and N. Miyachi, "Microfiber reinforced biodegradable starch ester composites with enhanced shock absorbance and prosessability," United States Patent no. 5.728.824, 12 pages, 1998.

[3] K. Nättinen, S. Hyvärinen, R. Joffe, L. Wallström, and B. Madsen, "Naturally compatible: starch acetate/cellulosic fiber composites. I. processing and properties," Polymer Composites, vol. 31, no. 3, pp. 524-535, 2010.

[4] G. Lammers, P. Tiitola, and J. Vuorenpää, "Process for the preparation of a starch ester," PCT International Patent, no. WO 9.829.455. 15 pages, 1998 .

[5] B. Madsen, R. Joffe, H. Peltola, and K. Nättinen, "Short cellulosic fiber/starch acetate composites - micromechanical modeling of young's modulus," Journal of Composite Materials. In press.

[6] H. L. Cox, "The elasticity and strength of paper and other fibrous materials," British Journal of Applied Physics, vol. 3, pp. 72-79, 1952. 
[7] W. D. Callister Jr., Materials Science and Engineering-An Introduction, Composites. U.S.A., chapter 16, John Wiley \& Sons, 6th edition, 2003.

[8] J. L. Thomason, "The influence of fibre length, diameter and concentration on the strength and strain to failure of glass fibrereinforced polyamide 6,6," Composites A, vol. 39, no. 10, pp. 1618-1624, 2008. 

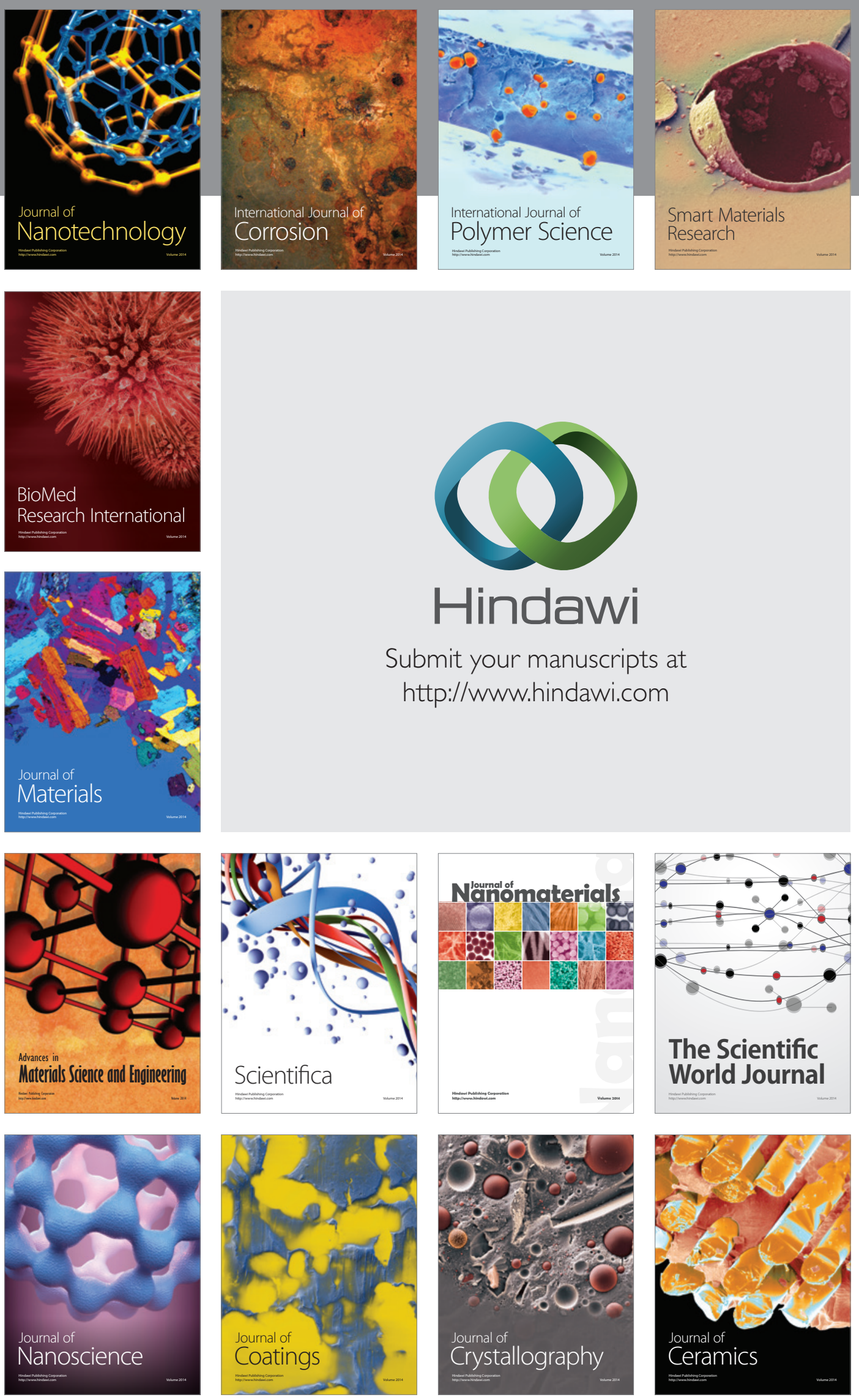

The Scientific World Journal

Submit your manuscripts at

http://www.hindawi.com

\section{World Journal}

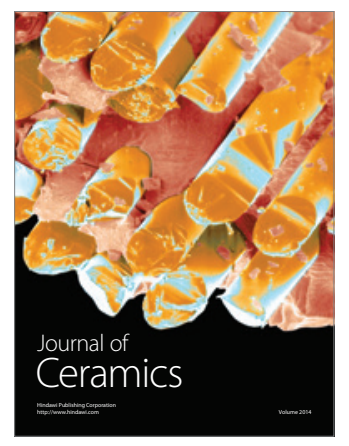

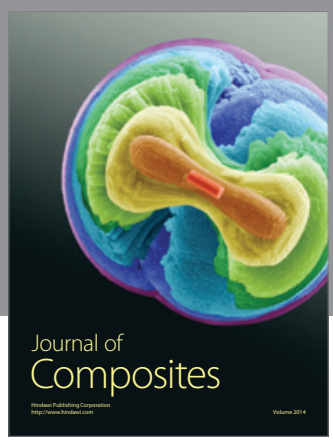
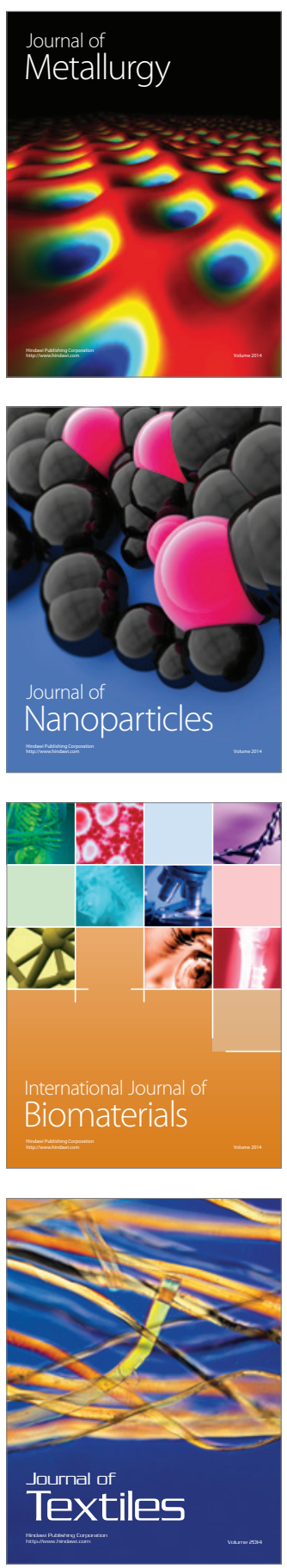